\title{
Prevenção e controle de infecção estafilocócica da glândula mamária com penicilina e estreptomicina associadas ao dimetilsulfóxido
}

\section{Prevention and control of staphylococcal infection of mammary gland with penicillin and streptomycin associated to dimetilsulfoxide}

\author{
José Eurico de Faria' ${ }^{1}$, José Britto Figueiredo², Elias Jorge Facury Filho², Orlando Raphael Lopasso \\ Júnior $^{2}$, Renato Dale'
}

\begin{abstract}
Resumo
Um total de 108 quartos mamários de 27 vacas de raças mestiças, predominando "Schwitz" com Zebu, foram tratados no início do período "seco" com uma combinação de penicilina e estreptomicina associada ao dimetilsulfóxido. As amostras de leite para exames bacteriológicos foram colhidas no final da lactação, na semana do parto e um mês após, na lactação seguinte. Os níveis de infecção nesses períodos foram, respectivamente, $24,1 \%, 25 \%$ e $36,1 \%$ dos quartos e $48,1 \%, 51,8 \%$ e $62,9 \%$ das vacas. As taxas de cura e de novas infecções durante o período "seco" e durante a lactação são analisadas e discutidas.
\end{abstract}

Palavras chave: mamite; prevenção e controle; mamite bovina; tratamento; glândula mamária; Staphylococcus aureus

\section{Introdução}

A mamite estafilocócica bovina é uma das doenças mais importantes do gado leiteiro. Décadas de controle têm apresentado resultados ainda não muito satisfatórios.

Os estafilococos, especialmente o Staphylococcus aureus, são os responsáveis pela maioria das infecções em Minas Gerais, outros estados brasileiros e no mundo (Figueiredo 1959; Smith et al., 1967; Langenegger et al., 1970; Faria, 1981; Hodges et al., 1984; Wats e Owens, 1989;Andrade, 1989). Além disso, são agentes que oferecem grande resistência aos tratamentos com antibióticos, especialmente em se tratando de infecções crônicas.

A associação da penicilina e estreptomicina, por via intramamária, demonstrou ser eficiente no tratamento das mamites estafilocócicas subclínicas (Andrade, 1989). Já em novilhas foi altamente efetiva para controlar mamite por $S$. aureus comparada com a resposta em vacas lactantes (Nickerson, 1993).

O uso de dimetilsulfóxido (DMSO) em preparações intramamárias, para aumentar a eficiência da terapia da mamite, se deve às suas propriedades de aumentar a permeabilidade das barreiras tissulares a uma grande variedade de drogas e de ser um excelente solvente, 0 que permite a utilização de ampla variedade de fármacos. Além de tudo, possui reconhecida ação antiinflamatória e antibacteriana (Lorda e Grimaldi, 1979).

O objetivo deste trabalho foi avaliar a eficiência da antibioticoterapia com penicilina e estreptomicina associadas ao DMSO, em veículo aquoso, na prevenção e controle de infecção estafilocócica da glândula mamária de vacas leiteiras, submetidas a desafios naturais.

\section{Material e métodos}

Foram utilizados 108 quartos mamários de 27 vacas de raças mestiças, predominando "Schwitz" com Zebu, com idade entre três e 17 anos e número de partos entre um e 13, de uma propriedade localizada no município de Florestal, Estado de Minas Gerais. Os animais foram mantidos em regime de semi-estabulação, com duas ordenhas mecânicas diárias. A higienização foi feita por meio de lavagem e desinfecção de úberes e tetas, antes da ordenha, e imersão de tetas, pós-ordenha, em desinfetante à base de iodo glicerinado.

Após a última ordenha da lactação todos os quartos eram infundidos com uma associação antibiótica contendo, por quarto, 100.000 U.I. de penicilina* (sendo 25.000 U.I. de benzilpenicilina potássica e $75.000 \mathrm{U}$.I. de benzilpenicilina procaínica) e 1.000 a $1.250 \mathrm{mg}$ de estreptomicina**, na forma de sulfato, em veículo aquoso contendo $20 \%$ de DMSO e aplicado em volume de $20 \mathrm{ml}$ por quarto, conforme empregado por Andrade (1989).

Trabalho com apoio financeiro do CNPq e FAPEMIG

' Departamento de Veterinária, Universidade Federal de Viçosa, 36571-000 Viçosa, MG, Brasil

2 Escola de Veterinária, Universidade Federal de Minas Gerais, 30161-970 Belo Horizonte, MG, Brasil

* Despacilina. Bristol-Myers Squibb Brasil S.A., Av. João Dias 1084, Santo Amaro, SP, Brasil

** Estreptomicina. Laboratórios Wyeth Ltda., Via Anchieta km 14, São Bernardo do Campo, SP, Brasil 
Com os cuidados de assepsia, na última semana de lactação, em ordenhas diferentes, antes da terapia antibiótica, duas amostras de leite de cada quarto foram colhidas e, na lactação seguinte, mais duas, uma na semana do parto e a outra um mês pós-parto.

Após pré-incubação a $37^{\circ} \mathrm{C}$ por 6 a $18 \mathrm{~h}$, as amostras de leite foram semeadas em ágar ${ }^{*}$ base, com $5 \%$ de sangue de carneiro e as placas incubadas a $37^{\circ} \mathrm{C}$ por $24-48 \mathrm{~h}$ (National Mastitis Council, 1969). As colônias de estafilococos isoladas, inicialmente identificadas pelas características macroscópicas em ágar sangue e características morfo-tinturiais pelo método de Gram, foram presuntivamente classificadas, em parte, de acordo com a tabela descrita em Kloos e Schleifer (1986) destacando-se as seguintes provas: hemólise em ágar sangue, prova de catalase, prova da coagulase, reação da desoxirribonuclease (DNase), fermentação do manitol, crescimento anaeróbico em meio líquido de tioglicolato de Brewer e reação de Voges-Proskauer.

Os quartos foram considerados infectados no final da lactação quando foi isolado $S$. aureus em, pelo menos, uma das duas amostras de leite colhidas na última semana da lactação. Com essa metodologia há probabilidade de $93,5 \%$ de se isolar o agente (Sears et al., 1990).

Através de tabela de contingência testada pelo quiquadrado foi estudada a dispersão de freqüência de vacas e quartos infectados e não infectados, dentro de cada período deste trabalho e da pesquisa feita no mesmo rebanho, sob as mesmas condições, porém com animais não submetidos a tratamento antibiótico (Faria, 1996).

\section{Resultados e Discussão}

Os números e percentagens de quartos infectados com S. aureus no final da lactação, semana do parto e um mês pós-parto são mostrados na Tabela 1 . A análise do número de quartos infectados e não infectados no final da lactação deste experimento com o de outro experimento desenvolvido com metodologia assemelhada (Tabela 2), feito em animais do mesmo rebanho, porém não tratados com antibióticos no início do período "seco", mostra que não houve diferença significativa entre eles $(p<0,05)$. 0 nível de infecção na semana do parto foi praticamente 0 mesmo observado no final da lactação anterior, pois havia somente um quarto a mais com infecção. Dos quartos infectados no final da lactação, $42,3 \%$ tornaram-se sem infecção na semana do parto (taxa de cura) e dos quartos sem infecção no final da lactação, $14,6 \%$ tornaram-se infectados na semana do parto (taxa de nova infecção) (Fig. 1). A taxa de cura deste trabalho $(42,3 \%)$ foi menor do que as verificadas por Loosmore et al. (1968), 64,1\%, utilizando três tratamentos intramamários: $500 \mathrm{mg}$ de cloxacilina benzatínica, $250 \mathrm{mg}$ de novobiocina sódica mais 300.000 U.I. de pencilina, e $500 \mathrm{mg}$ de espiramicina; por Ziv et al. (1981), 83,1\% e 83,8\%, para tratamentos com $500 \mathrm{mg}$ de cloxacilina benzatínica e com $100 \mathrm{mg}$ de nafcilina sódica mais $300 \mathrm{mg}$ de benzil penicilina procaínica mais $100 \mathrm{mg}$ de dihidroestreptomicina, respectivamente; por Boddie e Nickerson (1986), $80 \%$, quando utilizaram 1.000.000 U.I. de penicilina G procaínica e $1 \mathrm{~g}$ de dihidroestreptomicina, com metologia de inserção parcial da cânula de teta; e por Buddle et al. (1987), 90,5\%, quando utilizaram 500 mg de cloxacilina, por via intramamária.

Tabela 1 - Níveis de infecção por Staphylococcus aureus, de quartos mamários, na altura da secagem da lactação, na semana do parto e um mês após, em vacas tratadas com antibióticos

\begin{tabular}{llll}
\hline & \multicolumn{3}{c}{ Número e percentagens de quartos } \\
\cline { 2 - 4 } Períodos & Infectados & Não infectados & Total \\
\hline Secagem & $26(24,1 \%)$ & $82(75,9 \%)$ & $108(100 \%)$ \\
Semana do parto & $27(25 \%)$ & $81(75 \%)$ & $108(100 \%)$ \\
Um mês pós-parto & $39(36,1 \%)$ & $69(63,9 \%)$ & $108(100 \%)$
\end{tabular}

Secagem corresponde à última semana de lactação precedente.

Tabela 2 - Níveis de infecção por Staphylococcus aureus, de quartos mamários, na altura da secagem da lactação, na semana do parto e um mês após, em vacas não tratadas com antibióticos

\begin{tabular}{llll}
\hline & \multicolumn{3}{c}{ Número e percentagens de quartos } \\
\cline { 2 - 4 } Períodos & Infectados & Não infectados & Total \\
\hline Secagem & $26(20,9 \%)$ & $98(79 \%)$ & $124(100 \%)$ \\
Semana do parto & $31(25 \%)$ & $93(75 \%)$ & $124(100 \%)$ \\
Um mês pós-parto & $24(21,4 \%)$ & $88(78,6 \%)$ & $112(100 \%)$ \\
\hline
\end{tabular}

Fonte: Faria et al. (1996)

A análise do número de quartos infectados e não infectados, na semana do parto, dos animais deste experimento e do outro do mesmo grupo de autores (Tabela 2) mostra que não houve diferença significativa $(p>0,05)$ entre eles. A ausência de uma ação diferencial do tratamento com antibióticos entre os dois experimentos e, também, a discordância entre os resultados deste trabalho com os de outros autores podem ter sido devido a: (1) presença de amostras de $S$. aureus produtoras de penicilinases, uma vez que não foi realizado teste de sensibilidade para escolha da droga. As provas de susceptibilidade possibilitam o uso de um produto que tem melhor

\footnotetext{
* Merck S.A. Indústrias Químicas, Estrada dos Bandeirantes 1009, Rio de Janeiro, RJ, Brasil
} 
Períodos Número e percentagem (\%) de quartos examinados $(E)$, infectados $(P)$ e não infectados (N) em três períodos

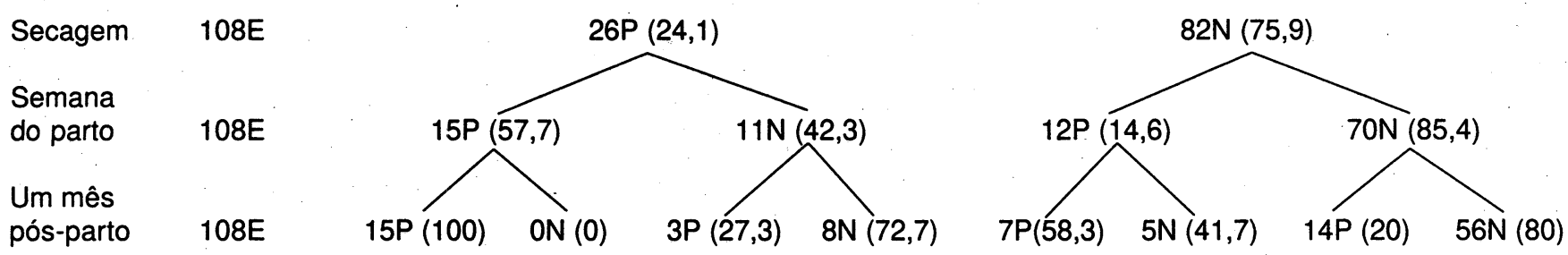

Figura 1 - Dinâmica da infecção de quartos mamários, por Staphylococcus aureus, do momento da secagem da lactação até um mês pós-parto da lactação seguinte, em vacas tratadas com antibióticos, em rebanho de Minas Gerais, 1994.

chance de bom sucesso quando Streptococcus $e$ Staphylococcus são as principais causas de mamite no rebanho (Hinckley et al., 1985), embora de acordo com Symposium (1982), quando o DMSO é adicionado a antibióticos específicos para tratamento de bactérias resistentes ao antibiótico, estes microrganismos tendem a perder a resistência, voltando a sensibilidade; (2) utilização de baixa dosagem de penicilina (100.000 U.I.), associada ao veículo aquoso, de liberação rápida, com baixo poder residual que pode ter contribuído para a baixa taxa de cura durante o período "seco" (42,3\%) e, para a alta taxa de nova infecção ocorrida durante o mesmo período $(14,6 \%)$. Entretanto esta mesma formulação foi efetiva em mamite estafilocócica subclínica, segundoAndrade (1989). Para Soback et al. (1990), essas concentrações no tecido são muito baixas quando a absorção é retardada por bases de liberação lenta. Taxas menores de nova infecção durante o período "seco", relatadas por Loosmore et al. (1968) e Ziv et al. (1981), foram, respectivamente, 1,6\% e 7,8\%,6,9\% e 6\% para três tratamentos diferentes; (3) período "seco" médio, muito longo, de 111,74 dias, com variação de 25 a 380 , que pode ter contribuído para um maior tempo de exposição das tetas e úberes às fontes de infecção, quando possivelmente já não havia nenhuma proteção pela associação antibiótica, possibilitando a re-infecção ou nova infecção; (4) presença de infecções crônicas, com abcessos e fibroses diversas, com o patógeno possivelmente encapsulado (micro abscessos submucosos) ou no interior dos fagócitos, que pode ter contribuído para a ausência de melhor sucesso no tratamento, não obstante a adição de DMSO à formulação que teve como um dos objetivos aumentar a permeabilidade de barreiras tissulares, possibilitando melhor penetração antibiótica, propriedades essas relatadas por Lorda e Grimaldi (1979), Symposium (1982) e Brayton (1986). O tratamento de mamite causada por $S$. aureusé geralmente ineficaz se as infecções são crônicas e acompanhadas por extensa formação de tecido de cicatrização (Nickerson, 1993).

O número médio de lactações foi de 4,07 , com variações de uma a 13 lactações e a idade média das vacas foi de 7,74 anos, com variações de três a 17 anos. Vacas mais velhas, com maior número de lactações, são mais propensas a adquirir infecção e são mais difíceis de serem curadas devido infecções crônicas, com abscessos bem desenvolvidos, embora Matthews et al. (1992) tenham verificaram em vacas primíparas maiores percentagens de quartos infectados na época do parto $(7,6 \%)$ e na quinta semana pós-parto $(3,5 \%)$ do que em vacas multíparas que foram $0,6 \%$ e $0,3 \%$, respectivamente. Esses números são bem inferiores aos do presente estudo, que foram $25 \%$ de quartos infectados na semana do parto e $36,1 \%$ um mês pós-parto. De acordo com Guterbock (1992), vacas de primeira lactação, com infecções recentes, são mais prováveis de se beneficiarem de terapia antibiótica, por causa de menos formação de microabscessos, do que vacas mais velhas.

$A$ análise do número de quartos infectados e não infectados com $S$. aureus, um mês após o parto, dos animais deste experimento e do outro executado por Faria (1996) revela que houve uma diferença estatisticamente significativa $(p<0,025)$ entre os dois experimentos e, de forma surpreendente, mostra que neste experimento, em que os animais foram tratados com antibióticos no início do período "seco", os mesmos apresentaram maior percentagem de quartos infectados $(36,1 \%)$ do que os animais do outro experimento $(21,4 \%)$. Na semana do parto, os animais incluídos nos dois experimentos apresentaram a mesma percentagem de quartos infectados (25\%).

No primeiro mês de lactação as taxas de cura e de nova infecção foram, respectivamente, $0 \%$ e $20 \%$ (Fig. 1). Taxa de nova infecção muito menor $(1,2 \%)$ foi encontrada por Loosmore et al. (1968) utilizando três grupos tratados com antibióticos diferentes. $O$ tratamento com antibióticos no início do período "seco" provavelmente não exerceu nenhuma influência na taxa de eliminação de infecção e prevenção de nova infecção durante o primeiro mês de lactação, pois sua eliminação da glândula é muita rápida. A penicilina persiste por $72 \mathrm{~h}$ em quartos mamários em lactação, após infusão intramamária (Egan e Meaney, 1985). Logo após o parto a associação penicilina/ estreptomicina é eliminada rapidamente (Nickerson, 1993). O tratamento com antibióticos pode até mesmo ter contribuído para a maior taxa de nova infecção (Fig. 1) e maior 
nivel de infecção (Tabela 1) no primeiro mês pós-parto, pela possibilidade de introdução de bactérias, presentes no canal da teta, para o interior da cisterna da teta ou até mesmo da cisterna da glândula, pela cânula usada para o tratamento, que era inserida totalmente na teta, às vezes chegando até à cisterna da glândula. Segundo Boddie e Nickerson (1986), a inserção completa da cânula pode transportar partículas de queratina colonizadas com bactérias para dentro das áreas das cisternas e induzir infecção intramamária. Além disso, a cânula pode forçar a queratina contra o interior da parede da teta, criando um lúmem ductal maior do que o normal; aumentando, portanto, a penetração bacteriana. Segundo Soback et al. (1990), quanto maior a prevalência de infecção intramamária na época da secagem do leite, maior é a probabilidade de introdução de bactérias do canal da teta para a cisterna da glândula, por meio de cânulas usadas em tratamento. No presente trabalho, na época da secagem do leite, $24,1 \%$ dos quartos estavam infectados com $S$. aureus, sendo maiores do que as prevalências encontradas por Ziv et al. (1981), em vacas $(13,5 \%)$ e por Trindad et al. (1990) em novilhas (12,3\%).

A terapia com antibióticos pode também ter eliminado patógeno de menor importância na glândula mamária, como Staphylococcus coagulase negativos e Corynebacterium bovis, muitas vezes responsáveis pela manutenção de um nível de leucocitose na glândula que atua como mecanismo de defesa contra os patógenos de maior importância, como é o caso do $S$. aureus. Esse efeito protetor da leucocitose é mencionado por Poutrel e Lerondelle (1980) citados por Trinidad et al. (1990). Os mesmos Trinidad et al. (1990) verificaram que o rebanho que tinha menor percentagem de quartos infectados com $S$. aureus tinha maior percentagem de quartos infectados com outros estafilococos.

O número e percentagem de vacas com úberes infectados com $S$. aureus no final da lactação, semana do parto e um mês pós-parto são mostrados na Tabela 3. A análise do número de vacas com úberes infectados e não infectados no final da lactação deste experimento com trabalho de Faria (1996) (Tabala 4) mostra que não houve diferença significativa entre eles $(p>0,05)$. Na semana do parto (Tabela 3) houve uma manutenção do nível de infecção presente no final da lactação, como ocorreu com relação aos quartos, pois havia somente uma vaca a mais com úbere infectado na época do parto (14 vacas) em comparação com o final da lactação que tinha 13 vacas. Das vacas com úberes infectados no final da lactação, $38,5 \%$ tornaram-se sem infecção na semana do parto (taxa de cura) e das vacas com úberes sem infecção no final da lactação, 42,9\% tornaram-se infectadas na semana do parto (taxa de nova infecção) (Fig. 2). Embora neste experimento a taxa de cura $(38,5 \%)$ tenha sido maior e a taxa de nova infecção, no período "seco" $(42,9 \%)$ tenha sido menor do que no experimento em que os animais não foram tratados com antibióticos no início do período "seco" (Faria, 1996), onde estas taxas foram, respectivamente, $25 \%$ e $53,3 \%$, quando se analisou o número de vacas com úberes infectados e sem infecção na semana do parto, nos dois experimentos, não se verificou diferença significativa entre eles $(-0>0,05)$. Mas, a percentagem de vacas infectadas neste experimento $(51,8 \%)$ foi menor do que a encontrada por Faria (1996), portanto diferente do que ocorreu com os quartos mamários, em que nos dois experimentos as percentagens foram idênticas (25\%) além dessas percentagens serem menos da metade das percentagens de vacas infectadas nos dois experimentos. A percentagem de vacas infectadas na semana do parto, neste experimento, foi bem superior às encontradas por Smith et al. (1967), 13,6\% e 5,9\%, em dois tratamentos com cloxacilina. Taxa de cura maior do que a do presente estudo foi encontrada por Loosmore et al. (1968), em $46 \%$ das vacas, quando utilizaram três preparações para o tratamento, sendo duas delas à base de penicilina. Entretanto quando se considerou somente a novobiocina associada à penicilina, a taxa de cura foi de $35,8 \%$, portanto, bem próxima à do presente estudo.

Tabela 3 - Níveis de infecção por Staphylococcus aureus, de úberes de vacas, na altura da secagem da lactação, na semana do parto e um mês após, em vacas tratadas com antibióti$\cos$

\begin{tabular}{llll}
\hline \multirow{2}{*}{ Períodos } & \multicolumn{3}{c}{ Número e percentagens de vacas } \\
\cline { 2 - 4 } & Infectadas & Não infectadas & Total \\
\hline Secagem & $13(48,1 \%)$ & $14(51,8 \%)$ & $27(100 \%)$ \\
Semana do parto & $14(51,8 \%)$ & $13(48,1 \%)$ & $27(100 \%)$ \\
Um mês pós-parto & $17(62,9 \%)$ & $10(37,1 \%)$ & $27(100 \%)$ \\
\hline
\end{tabular}

Tabela 4 - Níveis de infecção por Staphylococcus aureus, de úberes de vacas, na altura da secagem da lactação, na semana do parto e um mês após, em vacas não tratadas com antibióticos

\begin{tabular}{llll}
\hline & \multicolumn{3}{c}{ Número e percentagens de vacas } \\
\cline { 2 - 4 } Períodos & Infectadas & Não infectadas & Total \\
\hline Secagem & $16(51,6 \%)$ & $15(48 \%)$ & $31(100 \%)$ \\
Semana do parto & $20(64,5 \%)$ & $11(35,5 \%)$ & $31(100 \%)$ \\
Um mês pós-parto & $16(57,1 \%)$ & $12(42,9 \%)$ & $28(100 \%)$ \\
\hline
\end{tabular}

Fonte: Faria (1996)

A percentagem de vacas com úberes infectados no final da lactação foi de $48,1 \%$ (Tabela 3), superior às encontradas por Smith et al. (1967), 28,4\%, 31,9\% e 28,7\%, respectivamente, nos grupos utilizados como controle e para tratamentos com $0,2 \mathrm{~g}$ e com $1 \mathrm{~g}$ de cloxacilina; por 
Períodos Número e percentagem $(\%)$ de vacas examinadas $(E)$, infectadas $(P)$ e não infectadas $(N)$ em três períodos

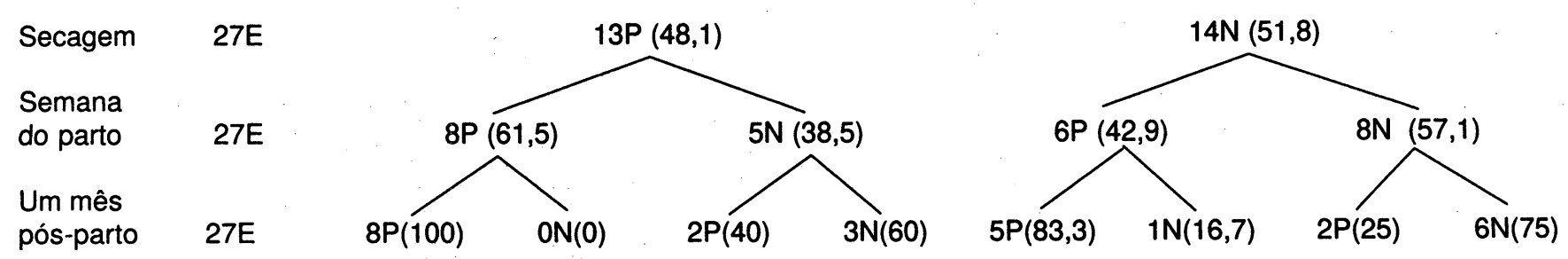

Figura 2 - Dinâmica da infecção de úberes de vacas, por Staphylococcus aureus, do momento da secagem da lactação até um mês pós-parto da lactação seguinte, em vacas tratadas com antibióticos, em rebanho de Minas Gerais, 1994.

Ziv et al. (1981) que foi de $29,3 \%$ das vacas e por Trindad et al. (1990), 37,1\% e $31 \%$ das novilhas para isolamento de secreções mamárias e canal da teta, respectivamente. A alta percentagem de vacas infectadas no final da lactação pode ter contribuído para uma maior taxa de nova infecção ou re-infecção durante o período "seco". O afirmado concorda com Soback et al. (1990) quando registraram que a taxa de nova infecção foi diretamente proporcional ao número de quartos infectados no final da lactação.

A análise do número de vacas com úberes infectados e sem infecção por $S$. aureus, um mês pós-parto, neste estudo e no outro (Faria 1996) mostra que não houve diferença significativa entre eles ( $p>0,05)$, embora o nível de infecção nesse período tenha sido pouco maior neste estudo $(62,9 \%)$ do que no outro $(57,1 \%)$. Na semana do parto o experimento com vacas não tratadas com antibióticos (Faria 1996) tinha maior nível de infecção $(64,5 \%)$ do que 0 do presente estudo $(51,8 \%)$. Essa análise em base de úberes de vacas se comportou diferentemente da análise feita no mesmo período em base de quartos mamários, quando se observou uma diferença significativa entre os dois experimentos, com um nível de infecção muito maior no presente estudo $(36,1 \%)$ do que no outro $(21,4 \%)$.

Os níveis de infecção nos três períodos estudados foram maiores quando calculados em base de vacas com úberes infectados (Tabela 3 ) do que em base de quartos mamários infectados (Tabela 1). Isto provavelmente ocorreu porque a maioria das vacas infectadas nesses periodos possuía apenas um ou dois quartos infectados (Tabela 5).

No primeiro mês de lactação as taxas de cura e de nova infecção foram, respectivamente, $0 \%$ e $25 \%$ (Fig. 2). Da mesma forma como verificado com os quartos, o tratamento com antibióticos não exerceu nenhuma influência positiva nesse período, nem sobre a eliminação e nem sobre a prevenção de infecções por S. aureus. As possíveis razões para isso são aquelas já discutidas para quartos mamários.
Tabela 5 - Freqüências de vacas sem e com infecção por Staphylococcus aureus, de acordo com o número de quartos infectados, na última semana da lactação (secagem), na semana do parto e um mês após, em vacas tratadas com antibióticos

\begin{tabular}{|c|c|c|c|c|}
\hline \multirow{2}{*}{$\begin{array}{l}\text { Número de quartos } \\
\text { infectados } \\
\text { por vaca }\end{array}$} & \multicolumn{3}{|c|}{ Número de vacas } & \multirow[b]{2}{*}{ Total } \\
\hline & Secagem & $\begin{array}{l}\text { Semana } \\
\text { do parto }\end{array}$ & $\begin{array}{l}\text { Um mês } \\
\text { pós parto }\end{array}$ & \\
\hline$\overline{0}$ & 14 & 13 & 10 & 37 \\
\hline 1 & 4 & 6 & 5 & 15 \\
\hline 2 & 7 & 5 & 5 & 17 \\
\hline 3 & 0 & 1 & 4 & 5 \\
\hline 4 & 2 & 2 & 3 & 7 \\
\hline Total & 27 & 27 & 27 & 81 \\
\hline
\end{tabular}

\section{Conclusões}

Nas condições em que foi realizada a presente pesquisa pode-se concluir que:

1. A terapia ao final da lactação, em dose única, com penicilina e estreptomicina em veículo aquoso, mesmo associada ao DMSO, não reduz o nível de infecção presente no final da lactação e esse nível de infecção é crescente na semana do parto e um mês após o parto.

2. Os níveis de infecção de úberes são maiores que os dos respectivos quartos mamários nos três períodos estudados.

\section{Abstract}

Prevention and control of staphylococcal infection of mammary gland with penicillin and streptomycin associated to dimetilsulfoxide

A total of 108 mammaries quarters of crossbred cows, predominating Schwitz with Zebu, were treated in the begining of the non lactant period with a combination of penicillin and streptomicin associated to dimethylsulfoxide. The strains of milk for bacteriological examinations were gotten in the end of the lactation, week of the parturition and a month later in the next lactation. The level of infec- 
tion in these periods were, respectively, $24.1 \%, 25 \%$ and $36.1 \%$ of quarters and $48.1 \%, 51.8 \%$ and $62.9 \%$ of cows. The cure and news infections taxes during the non lactant period and during lactation are analyzed and discussed.

Key words: mastitis; prevention and control; bovine mastitis; treatment; mammary gland; Staphylococcus aureus

\section{Referências bibliográficas}

Andrade JRA 1989. Mamite bovina em rebanhos da "bacia" leiteira de Belo Horizonte, Minas Gerais. I - Controle através de antibioticoterapia coadjuvada pelo dimetilsulfóxido (DMSO). II -Contribuição ao estudo epidemiológico. Tese de Mestrado em Medicina Veterinária, Escola de Veterinária da UFMG, Belo Horizonte, 98 pp.

Boddie RL, Nickerson SC 1986. Dry cow therapy: effects of method of drug administration on ocurrence of intramammary infection. J Dairy Sci 69(1): 253-257.

Brayton CF 1986. Dimethyl sulfoxide (DMSO):A review. Cornell Vet 76(1): 61-90.

Buddle BM, Herceg M, Ralston MJ et al. Reinfection of bovine mammary glands following dry-cow antibiotic therapy. Vet Microb 153: 191-199.

Egan J, Meaney WJ 1985. Persistence of detectable residues of penicillin and cloxacillin in normal and mastitic quarters following intramammary infusion. Vet Rec 116(16): 436-438.

Faria JE 1981. Isolamento de microorganismos potencialmente patógenos de leite, pele e meatos galactóforos externos de tetas e de mãos de ordenhadores. Tese de Mestrado em Medicina Veterinária, Escola de Veterinária da UFMG, Belo Horizonte, $55 \mathrm{pp}$.

Faria JE 1996. Infecção estafilocócica em vacas no final da lactação e no início da seguinte. Arq Bras Med Vet Zootec 48(5).

Figueiredo JB 1959. Estudo sobre a mamite bovina no municipio de Betim, Minas Gerais. Tese de Cátedra. Escola Superior de Veterinária da Universidade Rural do Estado de Minas Gerais, Belo Horizonte, 70 pp.

Guterbock WM 1992. Reducing antibiotic use in the treatment of clinical mastitis. Vet Med 87(12): 1229-1234.

Hinckley LS, Benson RH, Post JE et al. Antibiotic susceptibility profiles for mastitis treatment. J Am Vet Med Ass 187(7):
709-711.

Hodges RT, Jones VS, Holland JTS 1984. Characterization of staphylococci associated with clinical and subclinical bovine mastitis. $N Z$ Vet $J$ 32(9): 141-145.

Kloos WE, Schleifer KH 1986. Staphylococcus, p.1013-1035. In PHA Sneath, Bergey's Manual of Systematic Bacteriology, v.2, Williams \& Wilkins, Baltimore.

Langenegger J, Coelho NM, Langenegger $\mathrm{CH}$ et al. 1970. Estudo da incidência da mamite bovina na bacia leiteira do Rio de Janeiro. Pesq Agropec Bras Série Vet 5(3): 437-440.

Loosmore RM, Howell D, Adams AD et al. 1968. Drying-off therapy for bovine mastitis: a comparative field trial. Vet Rec 83(13): 358-360.

Lorda JAJ, Grimaldi JA 1979. Utilidade del DMSO en la medicacion intramamaria. Nuestra experiencia. Gaceta Vet 41(342): 430-434.

Matthews KR, Harmon RJ, Langlois BE 1992. Prevalence of Staphylococcus species during the periparturient period in primiparous and multiparous cows. J Dairy Sci 75(7):18351839.

National Mastitis Council 1969. Microbiological Procedures for the Diagnosis of Bovine Mastitis. University of New Hampshire Press, Washington, $27 \mathrm{pp}$.

Nickerson SC 1993. Eliminating chronic Staphylococcus aureus mastitis. Vet Med 88(4): 375-381.

Sears PM, Smith BS, English PB et al. 1990. Shedding pattern of Staphylococcus aureus from bovine intramammary infections. J Dairy Sci 73(10): 2785-2789.

Smith A, Westgarth DR, Jones MR et al. Methods of reducing the incidence of udder infection in dry cows. Vet $\operatorname{Rec} 81(20)$ : 504-510.

Soback S, Ziv G, Winkler M et al 1990 . Systemic dry cow therapya preliminary report. $J$ Dairy Sci 73(3): 661-666.

Symposium on Dimethyl Sulfoxide. Proceedings. Vet Med Small Anim.Clin 77(3):365-376.

Trinidad P, Nickerson SC, Alley TK 1990. Prevalence of intramammary infection and teat canal colonization in unbred e and primigravid dairy heifers. J Dairy Sci 73(1): 107-114.

Watts JL, Owens WE 1989. Prevalence of staphylococcal species in four dairy herds. Res Vet Sci 46(1): 1-4.

Ziv G, Storper M, Saran A 1981. Comparative efficacy of three antibiotic products for the treatment and prevention of subclinical mastitis during the dry period. Vet Quart 3(2): 74-79. 